\title{
Beyond the boundaries: Surgical repair of apical parietal pleural hernia
}

\author{
Domenico Galetta, $\mathrm{MD}, \mathrm{PhD},{ }^{\mathrm{a}}$ and Lorenzo Spaggiari, $\mathrm{MD}, \mathrm{PhD}^{\mathrm{a}, \mathrm{b}}$
}

\author{
From the a Division of Thoracic Surgery, European Institute of Oncology, IRCCS, Milan, Italy; and ${ }^{\mathrm{b}}$ Department \\ of Oncology and Hematology-Oncology-DIPO, University of Milan, Milan, Italy. \\ Disclosures: Authors have nothing to disclose with regard to commercial support. \\ Received for publication Nov 6, 2018; accepted for publication Nov 7, 2018; available ahead of print Dec 12, \\ 2018. \\ Address for reprints: Domenico Galetta, MD, PhD, Division of Thoracic Surgery, European Institute of Oncology, \\ Via Ripamonti 435, Milan, Italy (E-mail: domenico.galetta@ieo.it). \\ J Thorac Cardiovasc Surg 2019;157:e189-90 \\ $0022-5223 / \$ 36.00$ \\ Copyright (c) 2018 by The American Association for Thoracic Surgery \\ https://doi.org/10.1016/j.jtcvs.2018.11.017
}

Lung hernias are a rare entity, with approximately 300 cases reported in the literature. This rare clinical condition is generally defined as the protrusion of lung parenchyma beyond the confines of the musculoskeletal thorax.

First described by Roland in $1499,{ }^{1}$ lung hernias were classified by Morel-Lavalle in $1845^{2}$ according to the location. Approximately $65 \%$ to $83 \%$ of all lung hernias are thoracic and the remaining $35 \%$ are cervical. 3,4 The majority of lung hernias, about $80 \%$, are considered acquired (mainly traumatic in origin), whereas approximately $20 \%$ of reported cases are described as congenital. $^{5,6}$ In the majority of cases, cervical lung protrusions are seen most often during the first 3 years of life and generally resolve spontaneously.

Protrusion of the lung parenchyma into the neck is usually small, asymptomatic, and due to a defect in the thoracic outlet. Anatomically, as shown in Figure 1, the thoracic outlet is covered by parietal pleura and Sibson's fascia, which prevents the apex of the lung from bulging out to the neck.

Sibson's fascia, the membrane suprapleuralis, is the thickened portion of the endothoracic fascia extending over the cupola of the parietal pleura and reinforcing it. The fascia is attached to the inner border of the whole length of the first rib and to the transverse process of the seventh cervical/first thoracic vertebra. It blends into the parietal pleura. When weakened or torn, a cervical hernia may occur through a weak area (see Figure 1) of the anteromedial side.

Some authors report incidental discovery of apical pleural holes during video thoracoscopic procedures and hypothesize that they could be the precursors of cervical lung hernia.

Although the management of cervical hernia is usually conservative, the surgical approach for repairing the defect may be considered in case of symptoms such as airway obstruction, incarceration, cosmetic deformities, interference with usual activities, or recurrent infection.

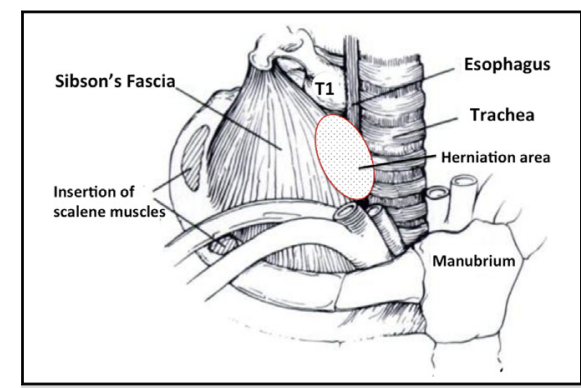

Schematic representation of the anatomy of the right thoracic inlet and related structures.

\section{Central Message}

Cervical lung hernia through a defect of Sibson's fascia and the parietal apical pleural is a rare condition in children. Thoracoscopic repair of this defect by prosthesis represents an ideal solution.

See Article page e187.
Surgical repair of cervical hernia has been performed both by cervical ${ }^{8}$ and thoracic ${ }^{9}$ approaches. The cervical approach provides excellent exposure but potentially higher risk of recurrence because the closure defect is more difficult than the transthoracic approach, the latter being a more invasive method with a large incision. The defect may be repaired primarily or using different tissues, such as muscle, periosteum, or prosthetic materials.

The first thoracoscopic approach to the repair of a cervical lung hernia was reported by Jheon and colleagues. ${ }^{10}$ They described their less-invasive technique in a 41-yearold obese man reporting excellent surgical view, cosmetic merit, and a proper approach to close the defect away from the pleural cavity.

In their case report, Amin and colleagues ${ }^{11}$ report the first case of a thoracoscopic repair of a Sibson's hernia in a pediatric patient. The authors ${ }^{11}$ provide a very interesting video of the surgical repair of the cervical hernia showing the different aspects of the thoracoscopic procedure, including the technique of the hernia reduction, the closure of the apical pleural defect, and the use of prosthesis for reinforcing the thoracic outlet.

For the reinforcement of the Sibson's fascia, the authors ${ }^{11}$ used a polytetrafluoroethylene patch that was secured with interrupted nonabsorbable sutures and endoscrews.

The material used for repair should be relatively inert to avoid excessive fibrous reaction. Thus, the use of biological 


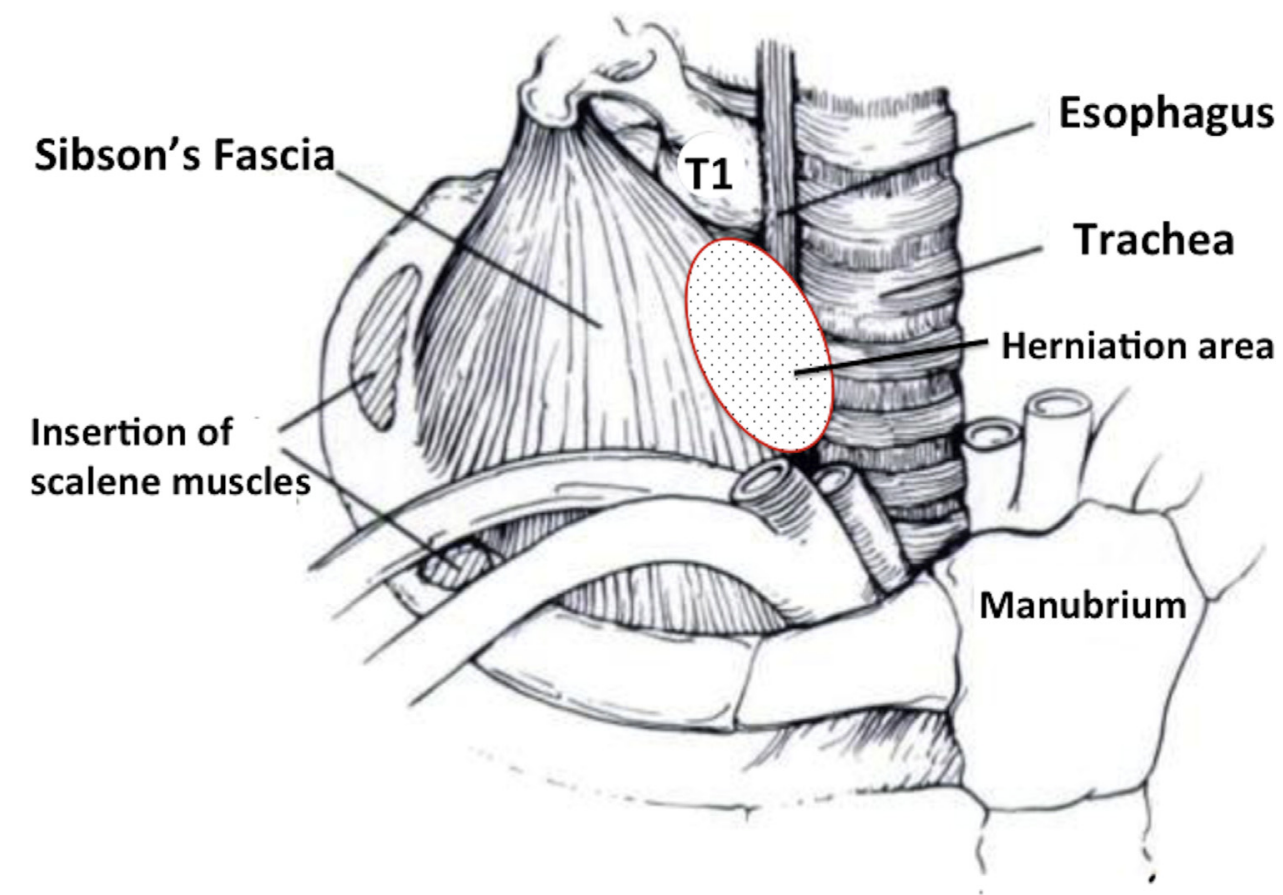

FIGURE 1. Schematic representation of the anatomy of the right thoracic inlet and related structures. The marked area represents the medial lung herniation zone were the lung apex may herniate following to a weakening or tearing of Sibson's fascia and producing a mass effect on esophagus and trachea.

materials as bovine or porcine pericardium may be advised. This biological material has some advantages: it is fully biocompatible and stiff enough to avoid shrinking and stretching; moreover, it carries a lower risk of infection and is easily adapted to cover the defect.

To fix the prosthesis in place, some authors use biological glue. ${ }^{12}$ Although the main advice for its use is for reducing the risk of mediastinal structure damage (vascular and nervous), it has been suggested in the literature that application of gluteraldehyde-based biological glues can cause tissue necrosis and nerve injury.

In the era of less-invasive surgery, Amin and colleagues ${ }^{11}$ have added a useful and comprehensive aspect of treating a rare but critical thoracic pathology.

\section{References}

1. Roland J. De Pulmonis Sanarpot. Liber III (cap) XXV. In: De Chavliae G, ed. Cyrugia. Venetiis. 1499:144.
2. Morel-Lavalle A. Hernie du poumon. Bull Mem Soc Chir Paris. 1845;1: 75-195.

3. Sonnet JR, O'Shea MA, Caushaj PE, Kulkarni MG, Sandstorm SH. Hernia of the lung: case report and literature review. Iranian J Med Sci. 1994; 163:410-2.

4. Glenn C, Bonekat W, Cua A, Chapman D, McFall R. Lung hernia. Am J Emerg Med. 1997;15:260-2.

5. Currarino G. Cervical protrusion in children. Pediatr Radiol. 1998;28: 533-8.

6. Moncada R, Vade A, Gimenez G, Rosado W, Demos TC, Turbin, et al. Congenital and acquired lung hernias. Thorac Imaging. 1996;11:75-82.

7. Galetta D, Serra M, Gossot D. Apical parietal pleural holes: what are they? Thorac Cardiovasc Surg. 2010;58:237-8.

8. Victor S, Muthurajan S, Sekhar TG, Gopinath R, Dhala B, Devi V, et al. Giant cervical herniation of an apical pulmonary bulla. J Thorac Cardiovasc Surg. 1987;93:141-7.

9. Lightwood RG, Cleland WP. Cervical lung hernia. Thorax. 1974;29:349-51.

10. Jheon S, Lee EB, Cho JY, Chang BH, Lee J, Kim KT. Thoracoscopic repair of cervical lung hernia. J Thorac Cardiovasc Surg. 2002;124:1030-1.

11. Amin R, Sullins VF, Mitchell ME, Arca MJ. Thoracoscopic repair of Sibson's hernia in a pediatric patient. J Thorac Cardiovasc Surg. 2019;157: e187-8.

12. Rahman M, Buchan KG, Mandana KM, Butchart EG. Bilateral cervical hernia with T1 nerve compression. Ann Thorac Surg. 2006;81:716-8. 